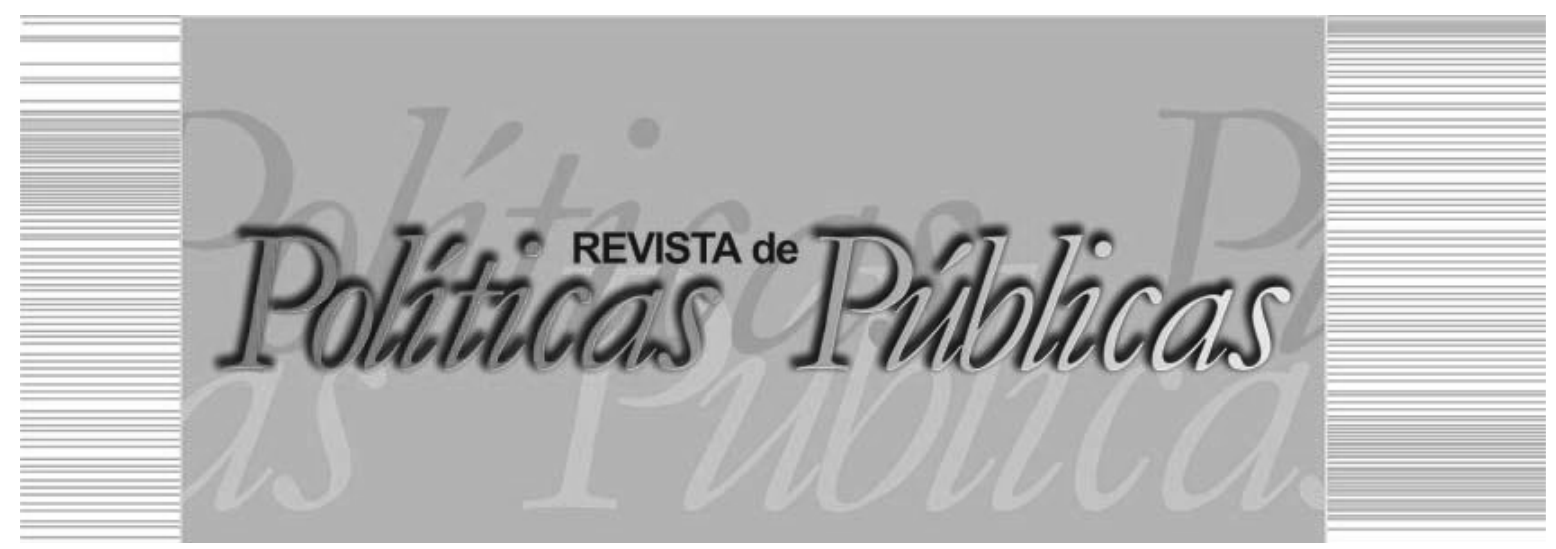

\title{
MICRODADOS RAIS E ESTUDOS SOBRE O MERCADO DE TRABALHO NO BRASIL
}

\author{
Valdenice Portela Silva ${ }^{l}$ \\ Marcus Eugênio Oliveira Lima
}

\section{Resumo}

O objetivo deste artigo é apresentar uma revisão integrativa de estudos sobreo mercado de trabalho no Brasil, publicados entre o período de 2006 e 2015, que utilizaram Microdados RAIS (Relação Anual de Informações Sociais).A partir das bases de dados Scientific Electronic Library Online(SciELO) e Instituto de Pesquisa Econômica Aplicada (IPEA) -dentre as 615 publicações consultadas - 10 artigos foram analisados, a maioria estudos teórico-empíricos. Concluiu-se que, embora seja pequeno o uso dos dados RAIS, estes consistem em um importante instrumento de análise do mercado de trabalho formal por contribuir com informações na elaboração de políticas públicas voltadas para redução do desemprego, melhoria da qualidade de emprego e inclusão de minorias no mercado de trabalho.

Palavras-chave: Mercado de trabalho, informações estatísticas, microdados RAIS, políticas públicas.

\footnotetext{
Bacharel em Administração, Mestre em Psicologia Social pela Universidade Federal de Sergipe (UFS). E-mail: valdenice.portela3@gmail.com / Endereço: Universidade Federal de Sergipe - UFS: Departamento de Psicologia. Av. Marechal Rondon, s/n. Rosa Elze. São Cristovão, SE. CEP: 49100-000

2 Bacharel em Psicologia, Doutor em Psicologia Social pelo Instituto Superior de Ciências do Trabalho e da Empresa, (ISCTE), Professor do Departamento e do Mestrado de Psicologia da Universidade Federal de Sergipe (UFS). E-mail: marcuseolima@gmail.com
} 


\title{
THE MICRODATA RAIS AND THE STUDIES THE LABOR MARKET IN BRAZIL
}

\begin{abstract}
The objective of this article is to present an integrative review of studies on the labor market in Brazil, published between 2006 and 2015, using Microdados RAIS (Annual Ratio of Social Information). From the Scientific Electronic Library Online (SciELO) and the Institute of Applied Economic Research (IPEA) - among the 615 publications consulted - 10 articles were analyzed, mostly theoretical-empirical studies. It was concluded that, although the use of RAIS data is small, they are an important instrument of analysis of the formal labor market by contributing information in the elaboration of public policies aimed at reducing unemployment, improving the quality of employment and inclusion of minorities in the labor market.
\end{abstract}

Keywords: Labour Market, statistical information, Microdata RAIS, public policies.

\section{INTRODUÇÃO}

A palavra estatística deriva do termo alemão statistik, criado pelo professor Gottfried Achenwall em 1749.Considerada nessa época como a ciência do Estado por descrever territórios e populações e fornecer informações técnicas aos dirigentes para que subsidiassem suas ações, tornou-se na Europa no século XVI, durante a monarquia, o espelho do príncipe numa época em que este era a própria encarnação do Estado. (SENRA, 1999).

O momento histórico era o da expansão comercial, ou seja, o momento da emergência da aceleração da circulação, do aumento da produção agrícola e não agrícola e do aumento da demanda geral, momento este que correspondeu, na época, à necessidade de estatísticas numéricas com a finalidade de se criar uma linguagem técnica comum e unificada aos estados emergentes. Nessa época, a atividade econômica se submetia aos interesses do Estado, pois não se tinha como objetivo aumentar a qualidade de vida da população, mas sim o poder do Estado. (SENRA, 1999).

As informações estatísticas sobre a população passam a municiar o governo, não apenas de dados como taxa de nascimento, de morte, de casamento, de doenças, de número de residentes, de renda, de tipo de trabalho exercido pelas pessoas, de raça/cor, mas também de uma tradução do mundo em traços concretos, mapas, gráficos e 
relatórios escritos, fomentando condições de governar, ou seja, de tomar decisões acerca da realidade socioeconômica circundante.

O processo de estruturação das informações estatísticas no Brasil está marcado por 3 períodos. O primeiro é quando, a partir das reuniões promovidas pelo Congresso Internacional de Estatística no século XIX, ocorre uma discussão acerca da necessidade de organização das informações estatísticas via coordenação destas por um órgão público. O segundo período se dá no momento em que no Brasil agências responsáveis pela produção de dados estatísticos. O terceiro e último período é aquele no qual o sucesso do planejamento no campo econômico deu margem a sua expansão no campo social, ou seja, entra no horizonte técnico a tentativa de dar conta de uma variada gama de problemas sociais. Isso representou um novo impulso à produção de dados e resultados estatísticos.

Cabe, neste momento, uma definição clássica e elementar desta ciência: "As estatísticas são representações numéricas da realidade a qual buscam mensurar. Em seu processo de construção, apoiam-se em interpretações teóricas que modelam aspectos da realidade e passam a criar seus próprios modelos de interpretação do real [...]" (PORCARO, 2000, p. 26).

Apesar dessa objetividade aparente, as estatísticas têm forte base semântica, por derivarem de diferentes significações que correspondem às grades interpretativas, constituindo expressões coletivas dentro de um determinado tempo e espaço. Funcionam como um retrato daquilo que se tem interesse em observar, uma fotografia que dá condições ao poder público de alterar a realidade social a partir dos dados que tem a sua disposição, os quais possibilitam a tomada de decisões em relação àquilo que é observado. (SENRA, 2001).

A produção estatística no Brasil, como fato histórico, continua fortemente apoiada na produção do Instituto Brasileiro de Geografia e Estatística (IBGE), cuja principal fonte de dados estatísticos é o Censo Demográfico, realizado em intervalos decenais em todo território nacional. Isso se deve não só à regularidade dos dados (a exceção do levantamento de 1990, quando por virtude da crise econômica não foi realizado), mas em razão da abrangência temática da pesquisa e da ampla cobertura geográfica, o que faz do IBGE hoje a principal fonte de informações para o planejamento de políticas em âmbito local e micro-local (distritos, bairros etc.). (ROCHA, 2006). 
Além das pesquisas censitárias há outras fontes de informações estatísticas, estaduais e municipais que proporcionam ao país informações demográficas e socioeconômicas com temas específicos que fornecem, por sua vez, informações para uma série de outras investigações.

As informações estatísticas podem ser geradas por meio de censos demográficos, pesquisas amostrais ou registros administrativos, cujos levantamentos populacionais são: a) contínuos (registros de óbitos, nascimentos e casamentos); b) periódicos (censos populacionais que ocorrem a cada 10 anos) e c) ocasionais.

Por conta de mudanças sociais como (i)o processo de democratização do país, (ii)a descentralização da ação pública e (iii) a focalização das políticas sociais, as informações estatísticas vêm, no decorrer do tempo, passando por diversas mudanças para atender às demandas sociais.

Como as informações censitárias não são suficientes para suprir todas as demandas sociais -uma vez que só são atualizadas a cada dez anos - são necessárias outras informações, como os registros administrativos. Estes, por se tratarem de levantamentos populacionais de aspectos contínuos, têm condições de atender às necessidades das instituições de pesquisa de contínua atualização dos seus dados, servindo como complemento dos dados gerados pelos censos demográficos. (FERREIRA, 2003).

As instituições de pesquisa que geram dados estatísticos acerca do mercado de trabalho no Brasil são: IBGE e o Ministério de Trabalho e Emprego (MTE). A primeira tem como bases estatísticas: a Pesquisa Mensal de Emprego (PME) que fornece informações sobre o emprego e desemprego nas principais regiões metropolitanas do país; os Censos Demográficos, realizados de 10 em 10 anos e as Pesquisas Nacionais por Amostra de Domicílios (PNAD) que ocorrem de 02 em 02 anos como uma forma de subsidiar os Censos Demográficos. Já o MTE faz uso de dois importantes instrumentos para registrar o emprego formal no país, que são: Relação Anual de Informações Sociais (RAIS) e Cadastro Geral de Empregados e Desempregados (CAGED).

Entre os produtores de Microdados há o IBGE e o MTE. Os Microdados consistem na menor fração de um dado e pode estar relacionado a uma pesquisa ou avaliação. De modo que, a partir da 
agregação de Microdados é construída a informação (QEDU ACADEMIA, [20--?]).

A RAIS foi criada pelo Decreto Lei 76.900 em 23 de dezembro de 1975 com o objetivo de prestar informações referentes ao mercado de trabalho formal brasileiro sobre empregados e não empregados. (BRASIL, 1975). Todos os empregadores são obrigados a fornecer anualmente uma série de dados sobre os empregados com os quais mantiveram vínculo empregatício no ano-base por meio do formulário RAIS que utiliza variáveis (discretas e contínuas) como: região, setor econômico, tamanho do estabelecimento, ocupação, sexo, grau de instrução, faixa etária, entre outros. Isto é, informações referentes a empregos, estabelecimentos, rotatividade e remuneração. (SABOIA; TOLIPAN, 1985).

Na literatura há3estudosque analisam a consistência estatística dos Microdados RAIS. O primeiro deles foi realizado por Saboia e Tolipan (1985). Os autores examinaram a credibilidade dos Microdados RAIS, produzidos pelo MTE, em relação aos dados gerados pela Pesquisa Nacional por Amostra de Domicílios (PNAD), realizada de dois em dois anos pelo IBGE, observando os seguintes fatores: a representatividade dos dados da RAIS, a distribuição setorial dos dados da RAIS e do PNAD e a cobertura do mercado de trabalho pelos dados da RAIS e do Censo Industrial.

Saboia e Tolipan (1985) concluem em seu estudo que, embora a RAIS seja uma base de dados nova - pois foi criada em 1975 - a mesma apresenta como ponto positivo tanto uma diversidade no elenco de dados disponíveis sobre o mercado de trabalho como um grau de qualidade satisfatório, provando ser um excelente instrumento de análise de curto e longo prazo do mercado de trabalho brasileiro.

O segundo estudo desenvolvido por Negri e outros (2001) também se restringiu a comparar os Microdados RAIS com os Microdados PNAD no que concerne ao mercado de trabalho formal. De forma que, quanto à confiabilidade dos Microdados RAIS, os autores confirmam no seu estudo que a RAIS mostrou ser uma fonte confiável de análise do mercado formal no Brasil, não só por sua natureza censitária, amplitude de informação, cobertura geográfica e dimensão temporal, mas por permitir análises longitudinais, "[...] o que viabiliza a investigação avançada de vários problemas relativos 
ao mercado de trabalho e à distribuição de renda com importantes impactos de política pública." (NEGRI et al., 2001, p. 26).

Por último, Paixão, Rosseto e Monçores (2012) compararam os Microdados RAIS com os Microdados PNAD em relação ao quesito raça/cor, constatando que o maior problema do critério hetero classificatório ${ }^{1}$ adotado pela RAIS, é o de apresentar uma maior vulnerabilidade em relação aos padrões étnico-raciais ainda hegemônicos no país, o que a levaria a um perfil de distribuição relativamente mais branco do que os Microdados PNAD produzidos pelo IBGE. De forma que, embora os autores reconheçam que a variável raça/ cor no formulário RAIS tenha razoável potencialidade para os futuros estudos na área acadêmica, aquela ainda precisa ser aprimorada e passar por análises futuras.

Ainda que os estudos apresentados tragam contribuições sobre a consistência estatísticas dos Microdados RAIS em relação aos Microdados PNAD, os mesmos não fornecem uma visão geral acercada produção científica a respeito do uso dos Microdados RAIS nos estudos sobre mercado de trabalho, pois não propõem uma revisão integrativa, mas sim estudos empíricos prioritariamente com o objetivo de validar os Microdados RAIS. Este viés prejudica a pesquisa sobre o número de estudos sobre mercado de trabalho que na atualidade fazem uso dos Microdados RAIS e suas respectivas utilizações das informações estatísticas.

Com a finalidade de suprir essa lacuna da literatura técnica, em especial, a falta de revisões acerca do assunto, este artigo tem por objetivo apresentar revisão integrativa de estudos publicados, entre o período de 2006 e 2015, que utilizaram os Microdados RAIS para analisarem o mercado de trabalho no Brasil.

\section{MÉTODO}

Elaborar-se-á uma revisão integrativa do levantamento feito sobre uma área ou tema de pesquisa, por meio do qual os autores avaliam os estudos selecionados, identificando as relações, contradições e inconsistências na literatura, proporcionando assim a síntese do conhecimento e a incorporação de estudos significativos na prática (UNIVERSITY OF WASHINGTON, 2010; SOUZA; SILVA; CARVALHO, 2010). Nesse sentido, foram realizadas as seguintes etapas: identificação do corpus da pesquisa, análise dos dados e resultados. 


\subsection{Corpus da pesquisa}

Neste estudo, foram utilizadas como fontes de pesquisa o periódico Pesquisa e Planejamento Econômico (PPE) publicado pelo Instituto de Pesquisa Econômica Aplicada (IPEA) e o Portal SciELO (http://www.scielo.br).A primeira foi escolhida porque, ao realizar estudos sociais e econômicos que dão apoio técnico e institucional ao Estado, é aquela com maior probabilidade de possuir artigos que fizeram uso de registros administrativos e estatísticos entre os anos de 2006 e 2015.A segunda fonte foi selecionada pelo motivo de ser a biblioteca eletrônica que abrange uma vasta coleção selecionada de periódicos científicos de origem nacional e internacional.

Foram utilizados, para busca dos artigos, os seguintes descritores e suas combinações na língua portuguesa: Microdados, RAIS, Mercado e Trabalho. Os critérios de inclusão definidos para a seleção dos artigos consistiram em: artigos publicados entre os anos 2006 e 2015 que tivessem usado os Microdados RAIS.

Os artigos selecionados foram recuperados na íntegra e, posteriormente, analisados a fim de se traçar um perfil das publicações nesses últimos 10 anos que usaram os dados RAIS. Os pontos investigados foram: título do artigo, objetivo, método, áreas de formação, atuação do primeiro autor e ano de publicação.

Quanto ao perfil metodológico, procedeu-se a classificação dos artigos em teóricos ou teórico-empíricos. Verificou-se ainda a abordagem utilizada, se qualitativa e/ou quantitativa, a partir do exame de participantes, instrumentos de coleta de dados e estratégias de análise empregadas. Em relação às referências, observou-se o número total e a porcentagem da literatura em português e outros idiomas, as áreas de formação e atuação do primeiro autor por meio de consulta do Currículo Lattes e a análise crítica dos trabalhos selecionados. Tudo isso entre os meses de fevereiro e agosto de 2016.

\section{RESULTADOS}

A busca por publicações que tenham feito uso dos dados RAIS no período de 2006 a 2015 na revista Pesquisa e Planejamento Econômico (PPE) e no portal SciELO se deu da seguinte maneira: entre as 615 publicações consultadas foram encontrados 10 artigos distribuídos entre as áreas da economia, administração, educação e saúde (01 na PPE e 09 no SciELO).Verificou-se que os 10 artigos 
foram publicados nos seguintes periódicos: Pesquisa e planejamento econômico, Estudos Econômicos, Caderno CRH, Revista Brasileira de Economia, Revista de Administração de Empresas, Revista de Administração Contemporânea, Educação e Pesquisa, Revista Brasileira de Estudos da População, Trabalho, Educação, Saúde, Revista Brasileira de Saúde Ocupacional.

Quanto ao idioma das referências utilizadas pelos artigos analisados, identificou-se que 4 dos artigos publicados na revista Pesquisa e Planejamento Econômico, Revista Brasileira de Economia, Revista de Administração de Empresas e Revista de Administração Contemporânea, apresentam predomínio da literatura internacional, principalmente do inglês. Enquanto apenas 1artigo utilizou referências nacionais e internacionais, as demais publicações apresentaram o predomínio da literatura em português. Nesse sentido, embora não tenha sido encontrada publicação, entre as selecionadas, de origem internacional, foi possível identificar um significativo uso do idioma estrangeiro, o que contribui para um maior nível de qualificação dos periódicos.

Gráfico 1 - Distribuição dos artigos por instituição de pesquisa

Fonte: Elaborado pelos autores, conforme dados do Instituto de Pesquisa Econômica Apliacda/Portal SciELO.

Além dos dados RAIS serem utilizados por especialistas, cujos estudos são publicados em periódicos bem qualificados, observa-se também que 4 dos trabalhos analisados têm os primeiros autores oriundos de instituições voltadas para o ensino das ciências econômicas, comprovando não só o predomínio desse tipo de estudo no campo da economia, mas o interesse do setor público pelos dados RAIS. Os principais autores dos 10 artigos analisados advêm de 06 instituições de pesquisa públicas e 03 privadas (Gráfico 1).

Quanto ao perfil metodológico, acompanhando a tendência da literatura internacional, todos os artigos são de natureza teórico-empírica. No que diz respeito à natureza do delineamento dos estudos teórico-empíricos, todos apresentaram uma abordagem quantitativa. Evidencia-se entre os estudos a existência de 03 eixos temáticos: 1) Trabalho e Emprego; 2) Trabalho e Saúde e 3) Trabalho e Tecnolo- 
gia. São distribuídos da seguinte forma: 06 Trabalho e Emprego, 03 Trabalho e Saúde e 01 Trabalho e Tecnologia.

\subsection{Trabalho e Emprego}

O artigo 01visou investigar os determinantes e a evolução do movimento simultâneo de entrada e saída dos empregados das empresas (churning ${ }^{2}$ ) que faz parte da rotatividade da mão-de-obra de uma economia. O método utilizado nesse estudo para analisar seu objeto de pesquisa foi o econométrico, o qual consiste em uma técnica de análise econômica que agrega a estatística, a matemática e a teoria econômica. (PEIXOTO, 2005). Nesse sentido, o primeiro artigo utilizou técnicas para tratamento de dados em painel, a partir de dados da RAIS desagregados por firmas (Microdados).

O segundo artigo analisou o ambiente institucional e organizacional do setor sucroalcooleiro do Brasil, especificamente no que se refere aos aspectos trabalhistas (legislação, negociações salariais), e apresentou indicadores para o período 1992-2005 sobre o mercado de trabalho: evolução do número de trabalhadores, escolaridade, idade, formalização e rendimento. Nesse artigo, o método utilizado foi análise descritiva dos dados RAIS e PNAD, a qual permitiu verificar que, no caso do Brasil, considerando-se os três setores (cana-de-açúcar, açúcar e álcool) conjuntamente, entre 2000 e 2005, houve um aumento expressivo de $52,9 \%$ do número de empregados formais, que passou de 642.848 empregados em 2000 para 982.604 em 2005 (MORAES, 2007).

O artigo 04 propôs um modelo econométrico para explicar o movimento do labor churning dos empregados formais no Brasil, centrando-se na substituição de trabalhadores que ocorrem por iniciativa das firmas, e não em razão das demissões voluntárias. O método usado nesse estudo consistiu em uma análise econômica que agrega a estatística por meio do tratamento de dados em painel corroborando para a realização do objetivo proposto pelo artigo. Os dados utilizados foram os Microdados RAIS (Relação Anual de Informações Sociais) do setor industrial da Região Metropolitana de São Paulo.

O sexto artigo também utilizou o método econométrico, por meio do qual as técnicas de análise dos dados RAIS e CAGED consistiram na análise de curva de crescimento, usando-se um modelo multinível, desenvolvida no software Hierarchical Linear 
Models (HLM) e na análise descritiva dos grupos de empresas, cuja informação foi usada no modelo multinível. Os resultados apontaram que o crescimento do emprego numa atividade econômica, localizada num município, está positivamente relacionado com o número de anos que este grupo de empresas é considerado um aglomerado. (BRITO et al., 2010).

$\mathrm{O}$ artigo 07 analisou o grau de confiabilidade dos dados RAIS nos estudos sobre as remunerações do professor do ensino médio no Brasil. Este estudo adotou o método de análise longitudinal, no qual o período analisado foi de 1996 a 2008, dois anos antes da implantação pelo governo federal do Fundo de Manutenção e Desenvolvimento do Ensino Fundamental e de Valorização do Magistério (Fundef), e da Lei n ${ }^{\circ}$ 9.424, 24 de dezembro de 1996 em 1998; como também os dois primeiros anos de vigência do Fundo de Manutenção e Desenvolvimento da Educação Básica e de Valorização dos Profissionais da Educação (Fundeb) e Lei n ${ }^{\circ} 11.494$, de 20 de junho de 2007. Foram usadas duas fontes indiretas: Instituto Nacional de Estudos e Pesquisas Educacionais Anísio Teixeira (INEP) e a RAIS.

Entre as limitações referentes à base de dados RAIS, a alimentação é uma delas, pois tal banco de dados apresenta informações incompletas ou ausentes quando se trata da remuneração de todos os professores da educação básica das escolas públicas.

$\mathrm{O}$ artigo 08 além de classificar e discorrer sobre as metodologias dos indicadores de segregação, bem como calcular os índices por faixa de renda em quatro períodos distintos com o intervalo de cinco anos (1994,1999, 2004 e 2009), também construiu uma aplicação empírica utilizando os dados RAIS. Dentre os resultados obtidos, notou-se uma tendência de diminuição de segregação das classes mais pobres. Ao passo que, em relação a outras classes, também foi possível observar que a segregação seguiu uma tendência decrescente ao longo dos anos, entretanto, de forma mais branda do que no primeiro grupo. (CARVALHO et al., 2013).

O método utilizado no oitavo artigo foi o econométrico, no qual, para o cálculo dos índices que englobam fatores espaciais, foi utilizado o software IpeaGEO, desenvolvido por pesquisadores do IPEA, que permite o cálculo do índice tanto para a categoria de um grupo como para a categoria de dois e de múltiplos grupos. 


\subsection{Trabalho e Saúde}

$\mathrm{O}$ artigo 03 propôs analisar a qualidade do emprego nas atividades de telecomunicações que, no Brasil, passaram por recente processo de reestruturação, seguido de privatização, caracterizando um novo cenário empresarial, marcado por inovações tecnológicas, expansão comercial e competição de mercado (MOCELIN, 2007). Com a aplicação do método longitudinal foi feita a análise da evolução das condições de trabalho nas telecomunicações no período entre 1994 e 2004 por meio da comparação dos seguintes dados: RAIS; Agência Nacional de Telecomunicações (ANT); Organizações e Sites especializados e de Estudos anteriores.

O artigo 09 - dado o contexto histórico e a existência das leis de ação afirmativa e de ampla legislação cidadã - descreve o cenário atual da inserção das pessoas com deficiência no mercado de trabalho. Este estudo apresentou como um dos seus objetivos avaliar o grau de formalização das pessoas com deficiência em face daquelas sem deficiência ou limitação funcional declarada.

O método adotado no nono artigo consistiu em uma análise descritiva dos dados: Microdados do Censo Demográfico de 2010 produzidos pelo IBGE e os dados RAIS gerados pelo MTE entre 2007 e 2010 acerca dos indivíduos com algum tipo de deficiência empregados no Mercado de Trabalho no Brasil.

Os resultados apontaram que em termos percentuais $4,9 \%$ das pessoas com deficiências estão no mercado formal de trabalho no Brasil. Como o número de vínculos formais, segundo os dados RAIS, é de apenas 306 mil, conclui-se que grande parte das pessoas com deficiência ocupadas está no mercado informal, exercendo atividades precárias, descontínuas e sem cobertura trabalhista e previdenciária. (GARCIA, 2014).

Diante a perspectiva histórico-cultural, tal qual a construção de um arcabouço jurídico e a existência de leis de ação afirmativa como o sistema de cotas, a seguinte pergunta se impõe: por que ainda persiste uma participação extremamente baixa de pessoas com deficiência no mercado de trabalho?

Evidencia-se, então, a partir da questão apresentada que entre os aspectos responsáveis por essa situação se encontram: acessibilidade precária; permanência de estereótipos e preconceitos; passivo escolar e na formação profissional; inadequação e insuficiência na 
legislação; questões culturais acerca da temática da deficiência que necessitam ser discutidas. Nesse sentido, percebe-se que as informações proporcionadas pelos dados RAIS podem servir de subsídios para a elaboração de políticas públicas tanto no âmbito da qualidade de emprego como para a redução do desemprego e da discriminação no mercado de trabalho.

Noutro conjunto de proposições, o artigo 10 estimou a prevalência dos transtornos mentais comuns (TMC) por meio de um estudo transversal que envolveu 41.639 trabalhadores de empresas cadastradas na Relação Anual de Informações Sociais (RAIS), no Sistema de Gerenciamento de Risco à Saúde na Indústria eno Serviço Social da Indústria (SESI). Para mensura dos TMC usou-se o

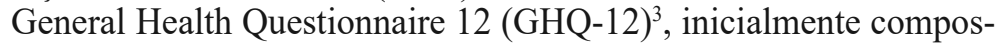
to de 60 itens, sendo posteriormente apresentado em versões resumidas, contendo 30, 20 e, por fim, 12 itens sem ter sua confiabilidade comprometida (FONSECA; ARAÚJO, 2014). As análises foram descritivas para conhecimento do perfil sociodemográfico da população e características do trabalho da população estudada, com a distribuição das proporções de trabalhadores entre os grupos ocupacionais da Classificação Brasileira de Ocupações e de regressão logística multivariada.

\subsection{Trabalho e Tecnologia}

$\mathrm{O}$ artigo 05 objetivou mensurar os impactos decorrentes da adoção da Tecnologia de Informação (TI) na produtividade dos trabalhadores da indústria da transformação brasileira. A técnica de análise aplicada foi a de corte transversal que concatenou as informações de inovação tecnológica, balanço contábil das firmas, características da mão-de-obra, desempenho externo e origem de capital controlador, advinda de base de dados exclusivamente construída para estapesquisa. Foram utilizados dados relacionados àindústriade transformação, entre o período de 2001 a 2003, fornecidos pela Pesquisa Industrial de Inovação Tecnológica (PINTEC) do IBGE, RAIS do TEM e Secretaria de Comércio Exterior (SECEX) do Ministério do Desenvolvimento, Indústria e Comércio Exterior (MDIC). 
MICRODADOS RAIS E ESTUDOS SOBRE O MERCADO DE TRABALHO NO BRASIL

\begin{tabular}{|c|c|c|}
\hline 主 & ڤ్ & స్తి \\
\hline 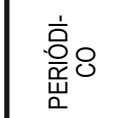 & 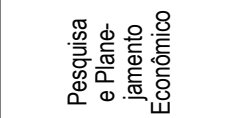 & 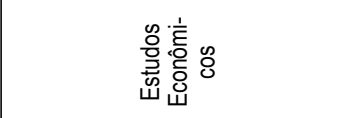 \\
\hline 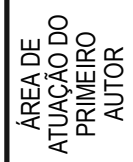 & 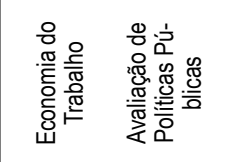 & 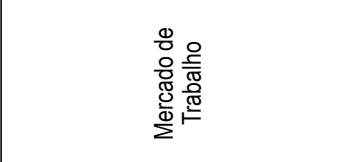 \\
\hline 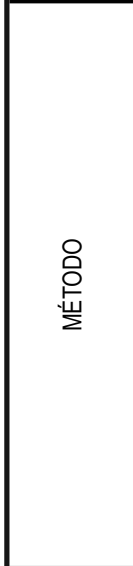 & 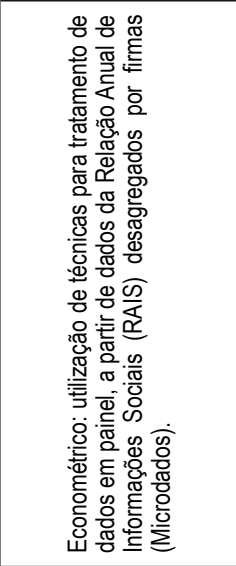 & 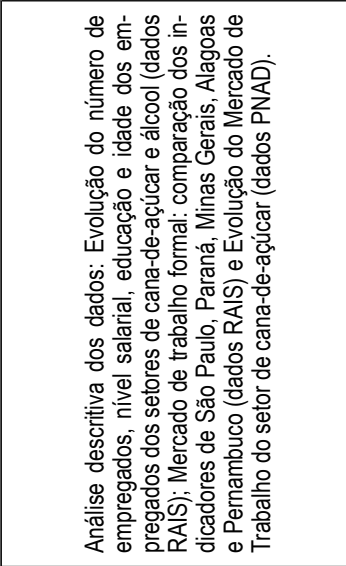 \\
\hline 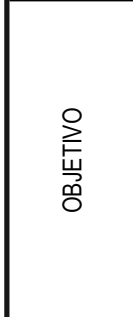 & 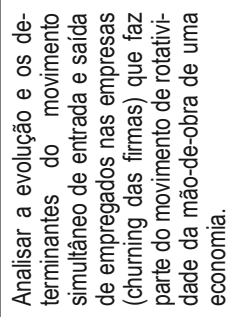 & 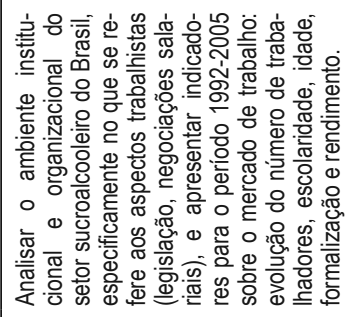 \\
\hline 올 & 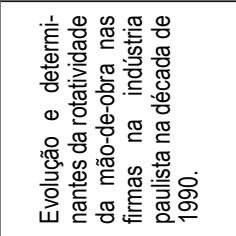 & 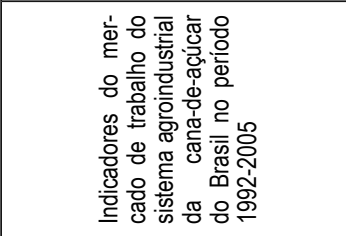 \\
\hline 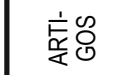 & 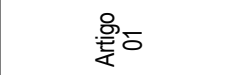 & 率ণ \\
\hline
\end{tabular}


Valdenice Portela Silva | Marcus Eugênio

\begin{tabular}{|c|c|c|}
\hline ప్రి & : & 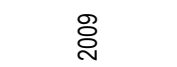 \\
\hline 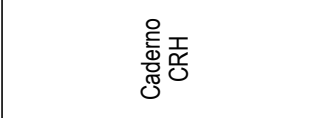 & 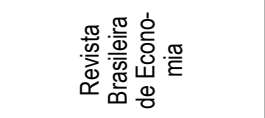 & 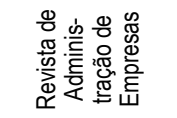 \\
\hline 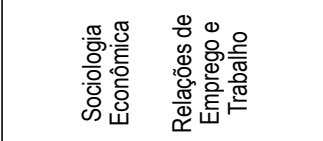 & 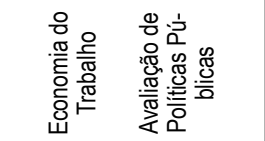 & 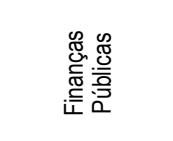 \\
\hline 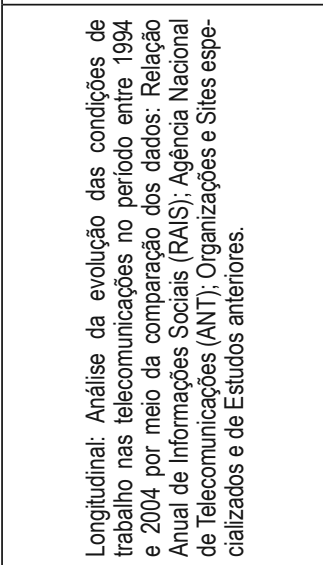 & 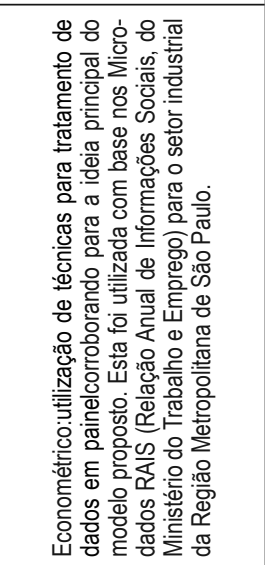 & 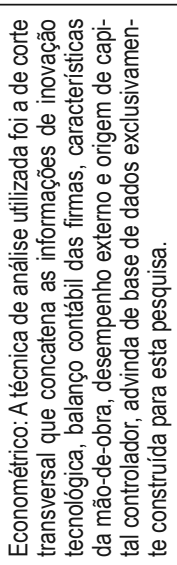 \\
\hline 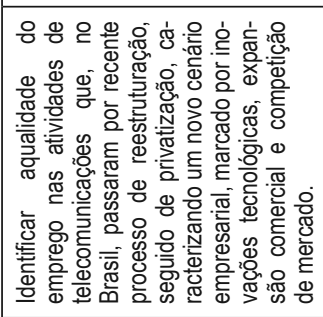 & 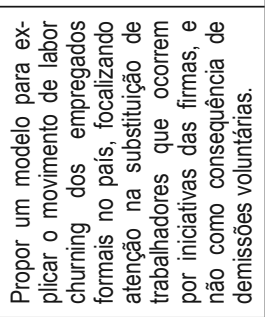 & 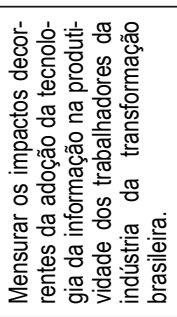 \\
\hline 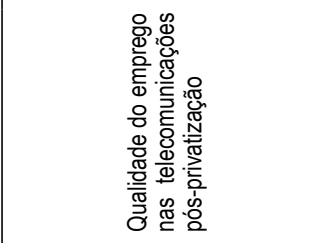 & 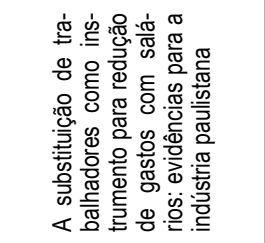 & 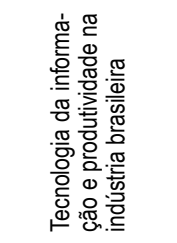 \\
\hline 安要 & 这 & 害 \\
\hline
\end{tabular}


MICRODADOS RAIS E ESTUDOS SOBRE O MERCADO DE TRABALHO NO BRASIL

\begin{tabular}{|c|c|c|}
\hline 옴 & $\stackrel{\sim}{\sim}$ & $\stackrel{\infty}{\stackrel{n}{n}}$ \\
\hline 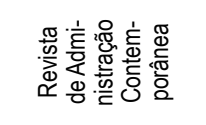 & 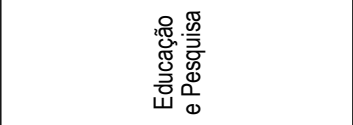 & 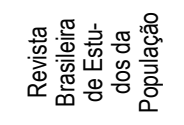 \\
\hline 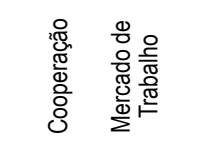 & 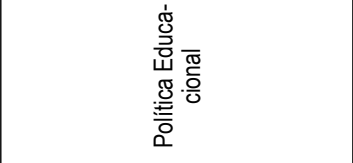 & 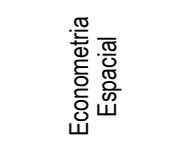 \\
\hline 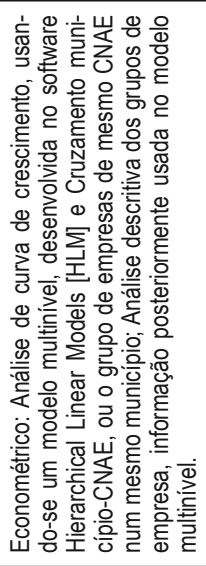 & 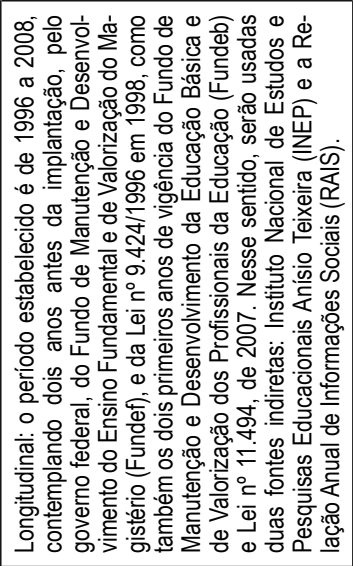 & 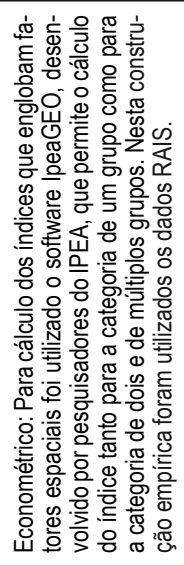 \\
\hline 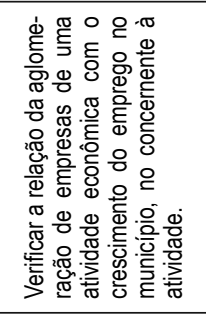 & 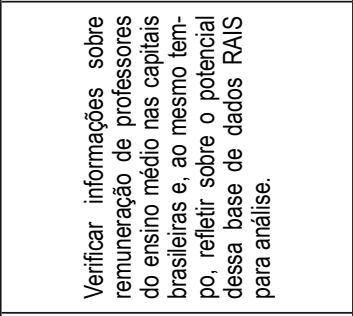 & 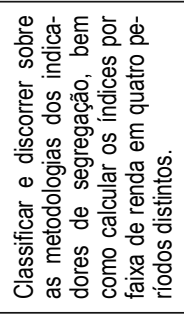 \\
\hline 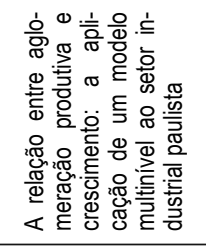 & 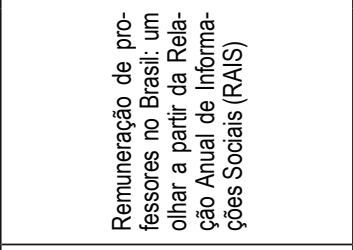 & 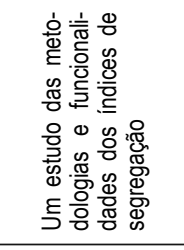 \\
\hline 走品 & 兽闹 & \\
\hline
\end{tabular}


Valdenice Portela Silva | Marcus Eugênio

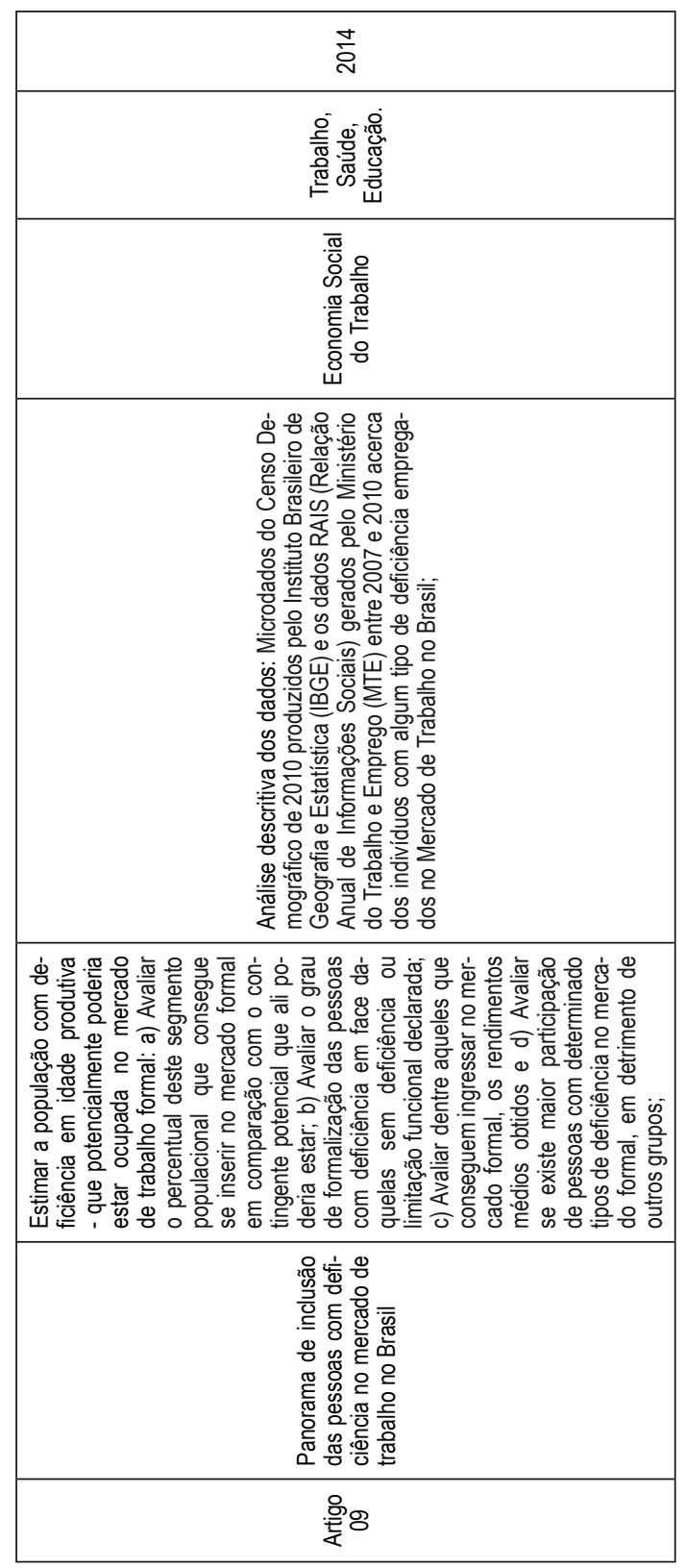


MICRODADOS RAIS E ESTUDOS SOBRE O MERCADO DE TRABALHO NO BRASIL

\begin{tabular}{|c|c|}
\hline$\stackrel{+}{\sim}$ & \\
\hline 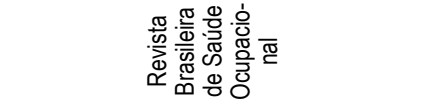 & \\
\hline 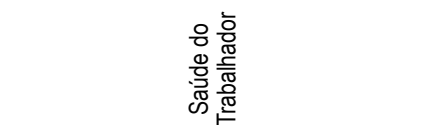 & \\
\hline 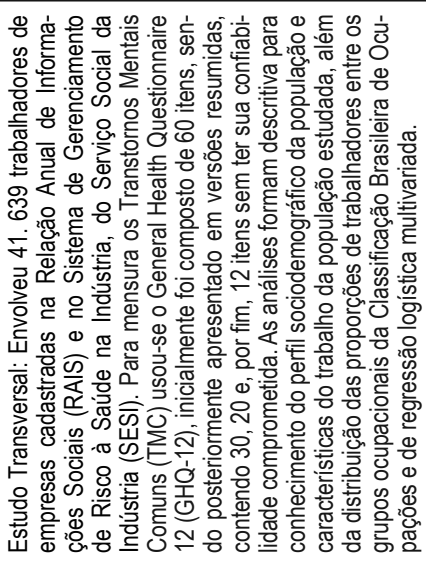 & 岀 \\
\hline 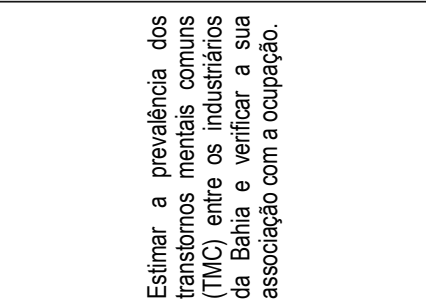 & 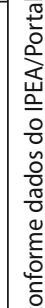 \\
\hline 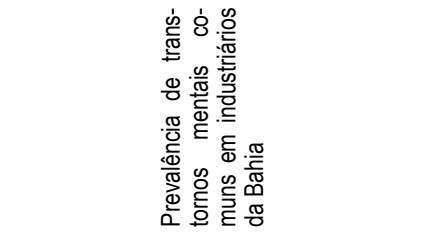 & 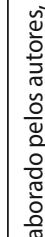 \\
\hline 용응 & \\
\hline
\end{tabular}




\section{CONCLUSÃO}

Considera-se que a revisão integrativa realizada oferece importantes contribuições para o conhecimento acerca da produção científica que tenha feito uso, entre os anos de 2006 e 2015, da base de dados RAIS como fonte de investigação. A partir do estudo, evidencia-se a existência de um reduzido volume de artigos $(1,6 \%)$ publicados, reafirmando a necessidade de se ampliar os estudos acerca de uma base de dados de significativa importância tanto para profissionais da área da economia e administração como para os que atuam em áreas como saúde coletiva e avaliação de políticas públicas.

Nota-se que a maioria das instituições de pesquisa que publicaram os artigos analisados é pública, pois por se tratarem de registros administrativos, os dados RAIS são um importante instrumento de análise do mercado de trabalho formal no Brasil por contribuir com informações na elaboração de políticas públicas voltadas para a redução do desemprego, melhoria da qualidade de emprego e inclusão de minorias no mercado de trabalho.

Neste sentido, em boa parte dos artigos analisados, os dados RAIS foram empregados com dados gerados por outras fontes de pesquisa (Ex.: Pesquisa Nacional por Amostra de Domicílios PNAD/IBGE) e usados tanto em estudos econométricos como longitudinais, sendo possível, neste último tipo de técnica, analisar um objeto de estudo por meio da evolução dos respectivos dados em determinado período de interesse do pesquisador.

Fora os artigos analisados terem sido publicados em periódicos de alto conceito Qualis (B1 e B2), percebe-se que o eixo temático cujos dados RAIS foram mais usados relaciona trabalho e emprego, viabilizando a possibilidade da elaboração de políticas públicas para o mercado de trabalho que garantam os direitos dos trabalhadores, bem como o desenvolvimento socioeconômico do país.

Os resultados apresentados estão em consonância com a literatura consultada. Porquanto, com base nos estudos analisados, a RAIS mostrou ser uma fonte confiável de análise do mercado de trabalho formal no Brasil, se for devidamente empregada com os dados estatísticos de outras fontes de pesquisa.

Entre as limitações do estudo, encontra-se o reduzido número de fontes de pesquisas consultado para o levantamento dos artigos que, entre 2006 e 2015, fizeram uso da base de dados RAIS: o Por- 
tal SciELO e a revista Pesquisa e Planejamento Econômico (PPE). Outra limitação consiste no fato de a RAIS ser uma base de dados brasileira, o que dificulta a localização de estudos estrangeiros que tenham feito uso dessa base de dados.

Como sugestão de estudo, todavia, é proposta aqui uma análise da contribuição dos dados RAIS na elaboração de políticas públicas e no desenvolvimento de ações afirmativas pelas empresas brasileiras em direção à valorização da diversidade e redução da discriminação no mercado de trabalho brasileiro. Identificando como esses dados podem auxiliar no cumprimento da norma de responsabilidade social empresarial.

\section{REFERÊNCIAS}

BRASIL. Decreto Lei n ${ }^{\circ} 76.900$, de 23 de dezembro de 1975. Diário Oficial [da] República Federativa do Brasil, Brasília, DF, 24 dez. 1975. Disponível em: <http://www.planalto.gov.br/ccivil_03/decreto/ antigos/d76900.htm>. Acesso em: 10 ago. 2016.

BRITO, E. et al. A relação entre aglomeração produtiva e crescimento: a aplicação de um modelo multinível ao setor industrial paulista. Revista de Administração Contemporânea, Curitiba, v. 14, n. 4, p. 615-632, jul./ago. 2010. Disponível em: $<$ http://www.scielo.br/ pdf/rac/v14n4/04.pdf>. Acesso em: 16 dez. 2015.

CARVALHO, A. X. Y. de et al. Um estudo das metodologias e funcionalidades dos índices de segregação. Revista Brasileira de Estudos da População, Rio de Janeiro, v. 30, n. 2, p. 567-594, jul./ dez. 2013. Disponível em:<http://www.scielo.br/pdf/rbepop/v30n2/12. pdf >. Acesso em: 16 dez. 2015.

FERREIRA, S. P. Produção e disponibilização de estatísticas: uma abordagem institucional.São Paulo em Perspectiva, São Paulo, v. 17, n. 3-4, p. 17-25, jul./dez. 2003. Disponível em:<http://www.scielo.br/ pdf/spp/v17n3-4/a03v1734.pdf>. Acesso em: 14 fev. 2016.

FONSECA, I. S. S.; ARAÚJO, T. M. de. Prevalência de transtornos mentais comuns em industriários da Bahia. Revista Brasileira de Saúde Ocupacional, São Paulo, v. 39, n. 129, p. 35-49, 2014. Disponível em:<http://www.scielo.br/pdf/rbso/v39n129/0303-7657rbso-39-129-0035.pdf $>$. Acesso em: 16 dez. 2015.

GARCÍA, V. G. Panorama da inclusão das pessoas com deficiência no mercado de trabalho no Brasil. Trabalho, Educação e Saúde, Rio de 
Janeiro, v. 12, n. 1, p. 165-187, jan./abr. 2014. Disponível em: $<$ http:// www.scielo.br/pdf/tes/v12n1/10.pdf>. Acesso em: 16 dez. 2015.

MOCELIN, D. G. Qualidade do emprego nas telecomunicações pósprivatização. Caderno CRH, Salvador, v. 20, n. 50, p. 299-319, maio/ ago. 2007. Disponível em: $<$ http://www.scielo.br/pdf/ccrh/v20n50/ v20n50a08.pdf $>$. Acesso em: 16 dez. 2015.

MORAES, M. A. F. Dias de. Indicadores do mercado de trabalho do sistema agroindustrial da cana-de-açúcar do Brasil no período 1992-2005. Estudos Econômicos, São Paulo, v. 37, n. 4, p. 875-902, out./dez. 2007. Disponível em: <http://www.scielo.br/pdf/ee/v37n4/ a07v37n4.pdf>. Acesso em: 16 dez. 2015.

NEGRI, J. A. de et al. Mercado de trabalho formal: comparação entre os Microdados RAIS e da PNAD. Brasília, DF: IPEA, 2001. Disponível em: $<$ http://repositorio.ipea.gov.br/handle/11058/2155>. Acesso em: 15 set. 2015.

ORELLANO, V.; MATTOS, E.;PAZELLO, E.A substituição de trabalhadores como instrumento para redução de gastos com salários: evidências para a indústria paulista. Revista Brasileira de Economia, Rio de Janeiro, v. 63, n.2, p. 179-207, abr./jul. 2009. Disponível em: $<$ http://www.scielo.br/scielo.php?script $=$ sci arttext\&pid=S0034-71402009000200005>. Acesso em: 24 jan. 2016.

PAIXÃO, M.; ROSSETO, I.; MONÇORES, E. Investigação sobre a qualidade da variável cor ou raça na RAIS através de um estudo comparativo com a PNAD e o IBGE. In: ENCONTRO ANUAL DA ANPOCS, 36., 2012, São Paulo. Anais eletrônicos... São Paulo: ANPOCS, 2012. p. 1-27. Disponível em: $<$ http://www.anpocs.com/ index.php/encontros/papers/36-encontro-anual-da-anpocs/gt-2/gt302/8349-investigacao-sobre-qualidade-da-variavel-cor-ou-raca-na-raisatraves-de-um-estudo-comparativo-com-a-pnad-do-ibge>. Acesso em: 15 set. 2015.

PEIXOTO, P. da S. O uso de modelos econométricos em empresas. 2005. 95 f. Trabalho de Conclusão de Curso (Graduação em Matemática Aplicada e Computacional) - Universidade de São Paulo, São Paulo, 2005. Disponível em: <http://www.ime.usp.br/ pedrosp/ Peixoto-ModelosEconometricos-2005.pdf>. Acesso em: 23 jan. 2016.

PORCARO, R. M. Produção de informação estatística oficial: na (des)ordem social da modernidade. 2000. 186 f. Tese (Doutorado em Ciência da Informação) - Escola de Comunicação, Universidade Federal do Rio de Janeiro, Rio de Janeiro, 2000. Disponível 
em:<http://ridi.ibict.br/bitstream/123456789/685/1/rosaporcaro2000. pdf $>$. Acesso em: 9 fev. 2016.

QEDU ACADEMIA. O que são Microdados? [S. 1.], [20--?].

Disponível em: $<$ http://academia.qedu.org.br/glossario/o-que-saomicrodados/>. Acesso em: 12 maio 2016.

ROCHA, S. G. A representação documentária de informações estatísticas: quando a ordem dos fatores altera o produto. $2006.98 \mathrm{f}$. Dissertação (Mestrado em Economia) - Universidade de São Paulo, São Paulo, 2006. Disponível em:<http://www.teses.usp.br/teses/ disponiveis/27/27151/tde-20052009-163801/pt-br.php>. Acesso em: 13 fev. 2015.

SABOIA, J. L. M.; TOLIPAN, R. M. L. A relação anual de informações sociais (RAIS) e o mercado formal de trabalho: uma nota. Pesquisa e Planejamento Econômico, Rio de Janeiro, v. 15, n. 2, p. 447-456, ago. 1985. Disponível em:<http://ppe.ipea.gov.br/index.php/ ppe/article/view/305/244>. Acesso em: 20 maio 2015.

SENRA, N. de C. Informação estatística e política pública: desafios futuros no presente. Transiformação, Campinas, SP, v. 13, n. 1, p. 5765, jan./jun. 2001. Disponível em: $<$ http://periodicos.puc-campinas. edu.br/seer/index.php/transinfo/article/view/1525/0>. Acesso em: 9 fev. 2016.

Informação estatística: política, regulação, coordenação. Ciência da Informação, Brasília, DF, v. 28, n. 2, 1999. Disponível em:<http://revista.ibict.br/ciinf/article/view/842>. Acesso em: 13 fev. 2015.

SOUZA, M, T, de; SILVA, M. D.; CARVALHO, R. de. Revisão Integrativa: o que é e como fazer. Einstein, São Paulo, v. 8, n.1, p. 102-106, 2010. Disponível em:<http://www.scielo.br/pdf/eins/v8n1/ pt_1679-4508-eins-8-1-0102.pdf>. Acesso em: 22 jul. 2016.

UNIVERSITY OF WASHINGTON. Writing a Psychology Literature Review.Washington, D.C., 2010. Disponível em: $<$ http:// faculty.webster.edu/woolflm/UWLitRev.pd $>$. Acesso em: 27 mar. 2016.

\section{Notas:}

1 No caso da base de dados RAIS, a informação sobre o quesito raça/cor é prestada pela empresa, ou melhor, pelo agente dentro da empresa responsável pelo setor de Recursos Humanos (próprio dono, algum preposto, etc.), de forma que o sistema de coleta da informação é hetero classificatório. 
2 O labor churning corresponde àquela parcela da rotatividade que diz respeito apenas ao movimento de substituição de trabalhadores por parte de cada firma, que pode ocorrer mesmo quando todas as firmas mantenham inalteradas o seu nível de emprego. (ORELLANO; MATTOS; PAZELLO, 2009).

3 Instrumento elaborado por Goldberg e Huxley (1992) com a finalidade de detectar distúrbios psiquiátricos não psicóticos nos contextos comunitários e ocupacionais, a partir de respostas relatadas pelo entrevistado no momento da pesquisa (FONSECA; ARAUJO, 2014). 